\title{
The ultrasonic navigating robot, WALKY
}

\author{
Håkan Neveryd 1,2 , Gunnar Bolmsjö 2 \\ ${ }^{1}$ CERTEC, Center of Rehabilitation Engineering, Lund University, Sweden \\ 2DPME, Dept. of Production and Materials Engineering, Lund University, Sweden
}

\begin{abstract}
A mobile robot system is being designed to work in a chemical laboratory environment for people with physical disabilities. We have found that chemical laboratories are good workplace alternatives to the office environment (see BACKGROUND). The main requirement for the workplace is to keep the work meaningful after the workplace has been robotized. The reasons for working with a mobile robot system are numerous:

- high flexibility for the disabled (the possibility to move between different workstations).

- only small changes in the physical environment are necessary.

- possibilities for the disabled and the non-disabled to use the same laboratory equipment.
\end{abstract}

\section{BACKGROUND}

The aim of this project is to get injured people back to work earlier and to increase employment possibilities for the disabled, including severely disabled. Earlier attempts to design service robots for the disabled in Sweden have been for the office environment. People with disabilities are neither more nor less interested or competent in administrative work than people without disability. We have also found that a laboratory could be a good working environment. We have found three different work-stations which are suitable for robotization:

- microscoping, for example cell exami-nation, cell and chromosome counting.

- blood group determination.

- culture analysing.

\section{THE DESIGN OF THE MOBLE ROBOT SYSTEM}

The mobile robot system consists of the following main components:

- Mobil base, Labmate

- Robot, Scorbot ER VII

- Sensor system

- Wireless radio modem

- Communication computer

- Local network

The outside dimensions of WALKY's base are $700 \times 750 \mathrm{~mm}$ and the height is $1350 \mathrm{~mm}$ (when the elbow is in the upper position). 


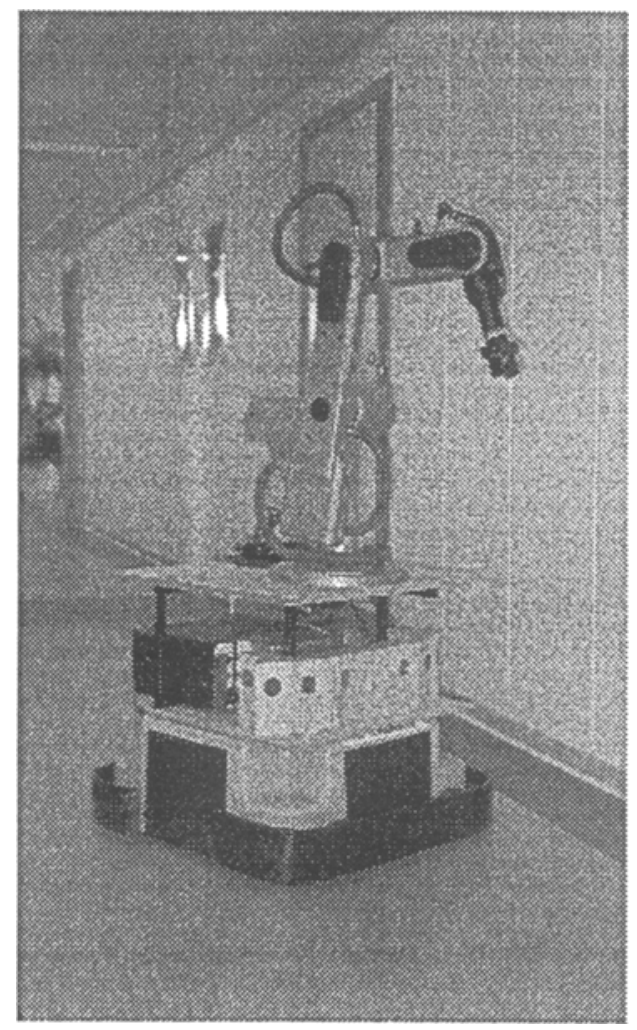

Fig 1 The ultrasonic navigating robot, Walky.

\section{SENSOR SYSTEM}

It is possible to connect 3 interface boards to the sensor system. To each interface board 8 ultrasonic and 8 infrared sensors can be connected.

The task for the sensors in this project is to measure distance. The infrared sensor technology has difficulties with:

- Sensitivity to ambient temperature

- Relatively directional

- Narrow and non uniform field of view

And the ultrasonic sensor technology has difficulties with:

- Object must be non porous

- Very directional $\left(10^{\circ}-30^{\circ}\right)$ with incident angle less than $15^{\circ}$

- Temperature sensitive

- False detection

In the beginning of the project we have chosen to only use ultrasonic sensors. 


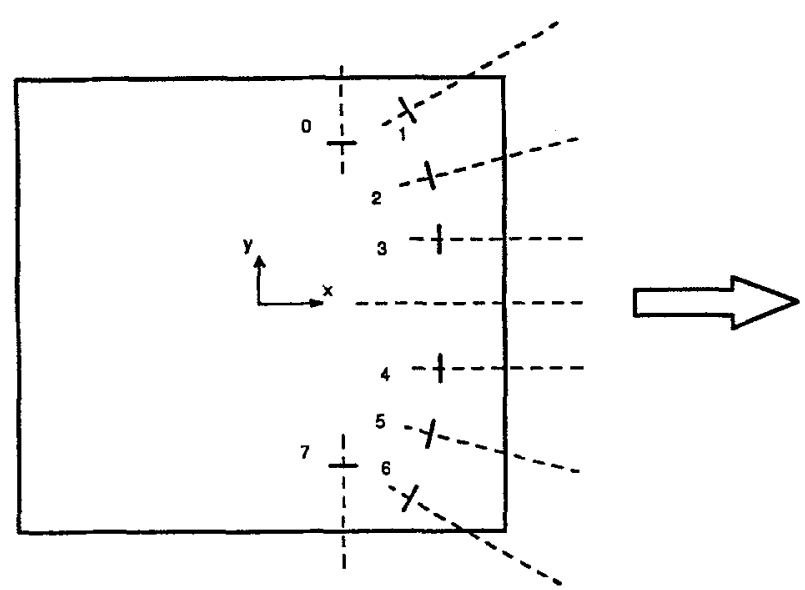

Fig 2 TheWALKY's sensor positions

The WALKY's sensor positions are a modified variant of the IPAMAR[1] mobile robot. The IPAMAR is a mobile autonomous robot (MAR) developed at the Fraunhofer Institute for Manufacturing Engineering and Automation (IPA) for carrying parts and products between the work cells of a factory.
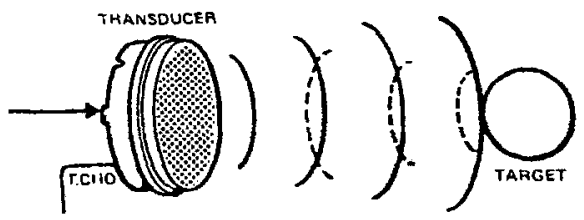

Fig 3 The Polaroid transducer

Ultrasound sensing, based upon the speed of sound, depends upon producing a high frequency; sound wave (above $20 \mathrm{kHz}$ ), transmitting the sound wave, and then measuring the time interval from the sound burst until a reflection returns from a target surface. A problem with ultrasonic sensors is that the speed of sound is a function of temperature also relative humidity.

The speed of sound varies only slightly with humidity, $\max 0,35 \%$ at $20^{\circ} \mathrm{C}$.

The speed of sound in air is determined from the following relationship:

$$
v_{c}=331.4 \cdot \sqrt{\frac{T}{273}}
$$

where $T$ is the ambient temperature in degrees Kelvin and $v_{c}$ is the speed of sound in $\mathrm{m} / \mathrm{s}$. If the temperature changes $28^{\circ}$, the variation of the speed of sound is $5 \%$. 


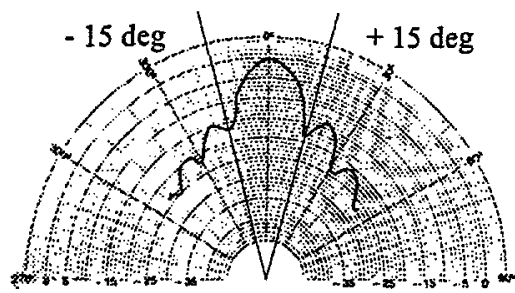

Fig 4 Typical beam pattern at $50 \mathrm{kHz}$

The Polaroid ultrasonic sensor [2] has full angle beam width (Figure 4) of $50 \mathrm{kHz}$ at approximately \pm 15 degrees. The sensor is capable of detecting the presence and distance of objects within a range of approximately $27 \mathrm{~cm}$ to $10,7 \mathrm{~m}$.

\section{SCENARIO}

The functionality of mobile systems can be described by the following scenario.

The operator is sitting by his/her workplace. He/she would like to fetch an object from another workplace. Through his/her computer the operator commands to the mobile robot system to go a predestined position at the other workplace. (The communication between the computer and the mobile robot system is handle by a wireless network.) If there isn't any obstacle between the start and end position, the mobile robot system drives directly to the end position.

If there is an obstacle, for example a chair, the mobile robot system drives in front of the chair. The sensor system gives enough information, for the mobile robot system to find a way around the obstacle. If there isn't any way around the obstacle the mobile system drives back to the start position.

Should any person obstruct the mobile robot system, it stops immediately due to information from the sensor system. If the sensor system would fail, the emergency system stops the robot system by physical contact between the person and the bumpers on the mobile base.

When the mobile system reaches the end position, the specified object is identified and grasped. Object identification is required, when the environment is unstructured. The grasping of the object and the transportation of the robot arm can be controlled by either pre-programmed routines or direct control. Also, a combination of pre-programmed routines and direct control will be possible.

\section{SAFETY}

When the evaluation of tasks has been done to select the meaningful work tasks which should be left after the robotization, the following research and development work remained:

- Safety.

- User friendliness.

The safety aspects should be solved by the sensor system [3]. If an object enters:

- the ignored zone, nothing happens. 
- the obstacle detection zone, the speed is slowed to $70 \%$ of the normal speed.

- the reflex zone, the speed is slowed to $50 \%$ of the normal speed and WALKY tries to avoid obstacie.

- the safety zone, a signal is transferred from the sensor to the controller of the mobile base. The base stops immediately. If this system fails, the bumpers on the Labmate stop the vehicle on contact.
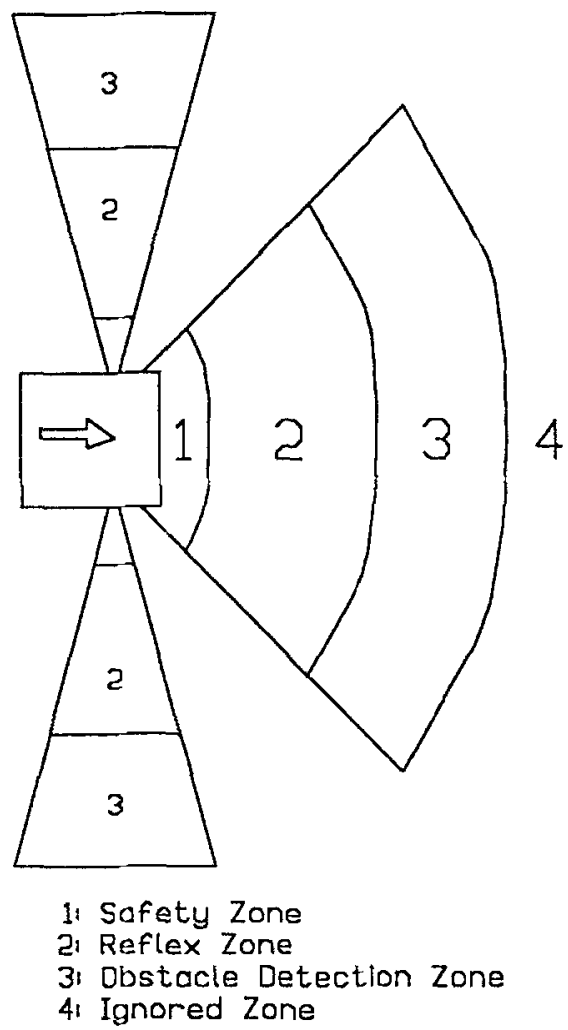

Fig 5 The detection zones

\section{USER INTERFACE}

The program moves the robot base with the aid of information from an Autocad drawing which describes the space in which the robot base can be manoeuvred. The drawing contains walls, doors, furniture and other objects which can limit the movements of the robot base.

The Autocad file must be in the DXF format, Autcad's format for file transfer between Autocad and other programs, where the drawing is defined as a set of Autocad primitives: Line, Circle, Point, PolyLine, Arc and Solid. The program stores the drawing as a list of these primitives. 
When the drawing is read, it is shown in a window within the main program window on the screen. To complete the initialization before the program is ready to use, the synchronization must be done. The synchronization connects the co-ordinate system of the robot base with the co-ordinate system of the program, so that the program knows where in the drawing the robot base is.

When the initialization is done, the user can move the robot base in two ways - either with the arrow keys on the keyboard or via the menus. When navigating the robot base from the menus the user points on the drawing shown on the screen with the mouse, where he or she wants the robot base to be moved. The program then calculates the best path to that point and moves the robot base according to that path.

The program is written in $\mathrm{C}++$ for the Microsoft Windows graphical environment and uses the ObjectsWindows package included with the Borland $\mathrm{C}++$ compiler.

\section{ACKNOWLEDGEMENTS}

The financial support under contract number 91-0414 of the Swedish Work Environment Fund is gratefully acknowledged.

\section{REFERENCES}

[1] Kacandes, Langen, Warnecke, A combined generalized potential field/ Dynamic path planning approach to collision avoidance for a mobile autonomous robot operating in a constrained environment, Proceedings of an International Conference of Intelligent Autonomous System, 11-14 December 1989 Amsterdam, The Netherlands

[2] Biber, Ellin, Shenk, Stempeck, The Polaroid ultrasonic ranging system, Presented at the 67th AES Convention, 31 October-3 November 1980, New York, USA

[3]Dietriche, Gelin, Ploix, Lambert, Mal-blanc, Assisted guidance device for electric wheelchair, The 1992 International Con-ference on Rehabilitation Robotics, 15-16 September 1992, Keele University, Staffordshire, England

\section{Håkan Neveryd \\ CERTEC/LTH \\ Lund University \\ Box 118 \\ S-221 00 LUND \\ SWEDEN}

e-mail: hakan.neveryd@certec.lth.se
Prof. G. Bolmsjö

Dept of Production and Material Engineer-ing/LTH

Lund University

Box 118

22100 LUND

SWEDEN

e-mail: gunnar.bolmsjo@mtov.lth.se 


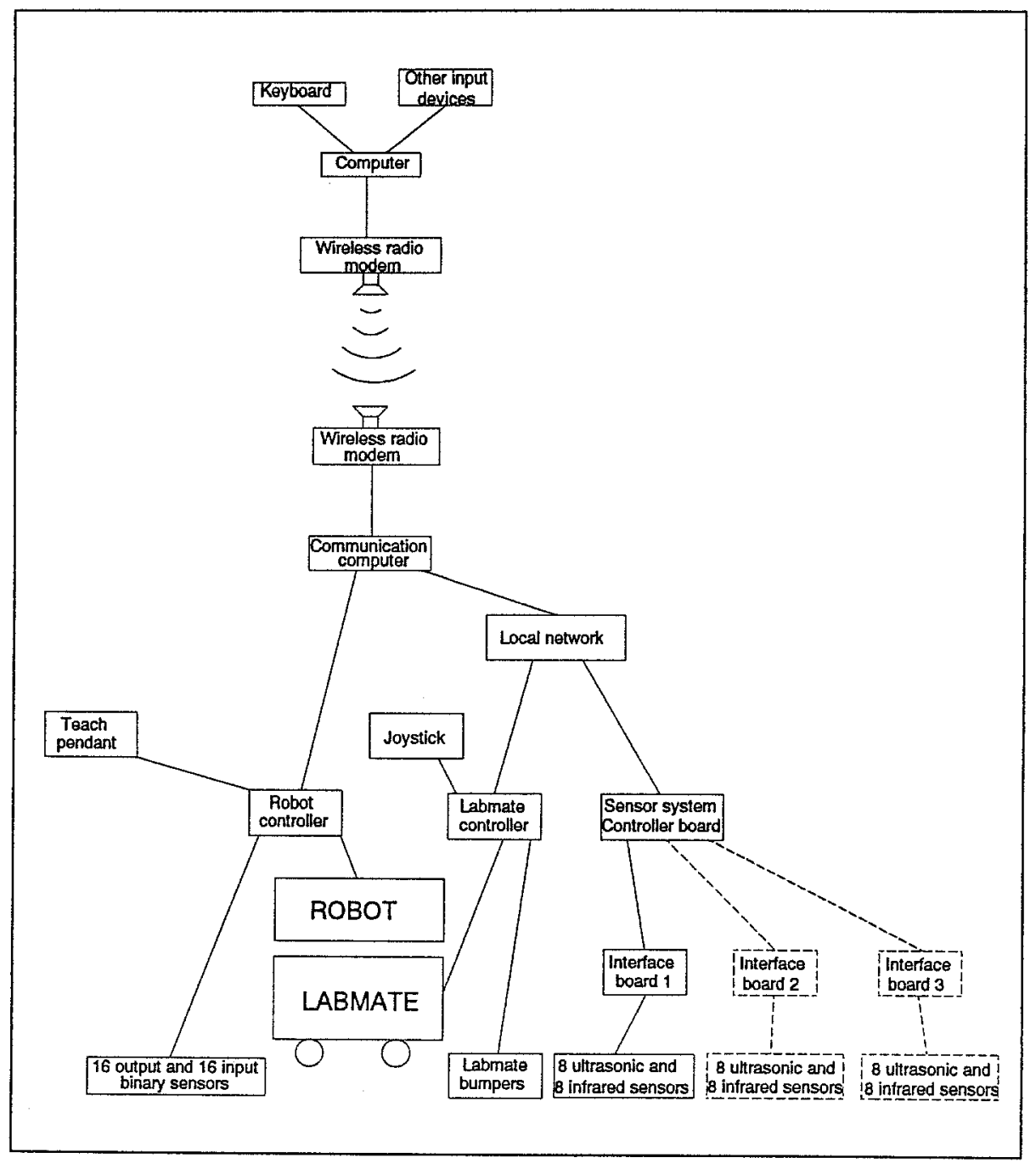

Fig 6 Diagram over the design of WALKY 